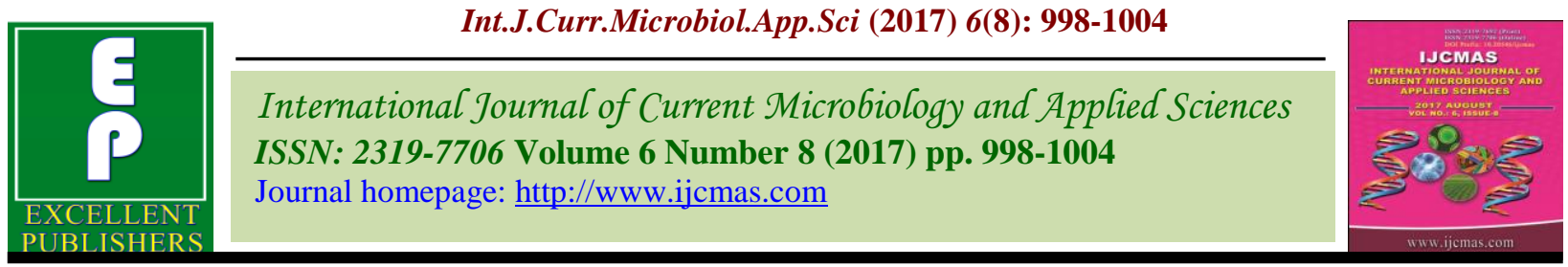

Original Research Article

https://doi.org/10.20546/ijcmas.2017.608.123

\title{
Antibiotic Susceptibility of Streptococcus pyogenes Isolated from Otitis Media and Tonsillitis among Children Patients
}

\author{
Abbas Zeki Mahdi ${ }^{1}$, Jawad Hamid Hassan ${ }^{1}$ and Khalid Sh. Jebur ${ }^{2 *}$ \\ ${ }^{1}$ Iraqi Ministry of Health, Medical City, Baghdad, Iraq \\ ${ }^{2}$ National Center for Occupational Health and Safety, Iraq \\ *Corresponding author
}

\section{A B S T R A C T}

Keywords

Tonsillitis, Otitis media, Strep.

pyogenes, Antibiotic susceptibility profile.

\section{Article Info}

Accepted:

14 June 2017

Available Online:

10 August 2017
Two hundred specimens (100 males and 100 females) were included, through (100) swabs of otitis media and (100) swabs of tonsillitis. These swabs had obtained from patients consulted to different hospitals of Baghdad city during the period from 10 March 2017 to 12 May 2017. There were 27(27\%) positive isolates for Strep. pyogenes, which obtained from patients with age ranged from less than6 years, who suffered from tonsillitis and ear infections. The phenotypic characterizations of twenty-seven isolates (13.5\%) of Strep. pyogenes, which had obtained, showed characteristic colony morphology when cultured on different agar plates, microscopic appearance and biochemical tests. Twenty-seven (27) isolates of Strep. pyogenes were tested for their antibiotics susceptibility against eleven antibiotics by using Kirby-Bauer disc diffusion methods on Muller Hinton agar. Results of antibiotic susceptibility had showed different levels of sensitivity and resistance.

\section{Introduction}

Streptococcus pyogenes is Gram-positive, Non-motile, and non-spore forming spherical cocci with 0.5 to $1.0 \mu \mathrm{m}$, which can form long chains in liquid medium (1). Streptococcus Pyogenes causes several infections as pharyngitis, tonsillitis, cellulitis, necrotizing fasciitis, pneumonial bacteremia and ear infection, besides post infectious sequelae like acute rheumatic fever (6). Pathogenesis of Streptococcus pyogenes infections is multi factorial, as suggested by the number and wide array of virulence determinants possessed by cell-surface molecules which had reported as possible adhesions due to their ability to bind specific components of
Pathogenic bacterial strains that develop or acquire resistance to one or more first-line antibiotics pose numerous challenges to healthcare. These resistances are including increased patient morbidity and mortality, prolonged illness duration, and more expensive disease control measures $(3,4)$. Antibiotics resistance patterns were a serious and growing phenomenon in contemporary medicine and had emerged as one of the preeminent public health concerns of the $21 \mathrm{st}$ century. So that, there had a growth in the change and severity of Streptococcus Pyogenes contagions, including those that 
were aggressive. However, Streptococci bacterium remnants vulnerable to penicillin, some strains had recognized to be resilient to macrolides, such as erythromycin, as well as tetracycline and clindamycin. This can cause Streptococcus spp. isolates to be exposed to ineffective antibiotics treatments and develop further resistance (5). Moreover, the rapidly growing problems of antibiotic resistant Streptococcus pyogenes have existed and increased according to severity of pathogenic agents, immunity of individuals, geographical locations and investigators $(7,8)$. Furthermore, several genetic elements involved in antibiotic resistance had horizontally transferred among different Lancefield groups and within species $(9,10)$.

\section{Materials and Methods}

\section{Patients}

Two hundred patients (100 males and 100females) with age less than 6years, who suffered from tonsillitis and ear infection, that presenting to five hospitals of Baghdad city during the period from 10 March 2017 to 12 May 2017.

\section{Specimen's collection}

Tonsillitis and otitis media specimens were collected using cotton swabs. These swabs had directly inoculated onto the plates of transport medium, then incubated overnight at $37^{\circ} \mathrm{C}$ (14). The history for each case had recorded in a questionnaire at case sheets.

\section{Identification of Streptococcus pyogenes}

\section{Culturing of throat and ear specimens}

Each swab was immediately taken by transport medium and then inoculated on blood ager plates and 5\% sheep blood agar plates and incubated at $(5-10 \%) \mathrm{CO}_{2}$ to prove the facultative anaerobic-enriched atmosphere for 24 hours at $37^{\circ} \mathrm{C}$ (14). In addition, different media had used for laboratory isolation and identification.

\section{Colony morphology and microscopic}

A single colony had taken from each primary positive culture and its identification depended on the morphology properties (colony, size, shape, color and natural of pigments, translucency, edge, elevation and texture).

Suspected colonies had selected and investigated by gram stain to observe as specific color reaction, shape aggregation and specific intracellular compounds after staining the bacteria by gram stains, tests had done to reach the final diagnosis (15).

\section{Statistical analysis}

Statistical program had performed by SPSS (V-15). Descriptive statistics had included tables that create (number, percentage, mean and standard error (16).

\section{Results and Discussion}

\section{Isolation and identification}

$\begin{aligned} & \text { Macroscopic and microscopic } \\ & \text { characterizations }\end{aligned}$

From two hundred samples had obtained from tonsillitis and otitis media infections patients presenting to five hospitals in Baghdad city. The phenotypic characterization of twentyseven isolates (27\%) of Streptococcus pyogenes, which had obtained showed characteristics colony morphology when cultured on blood agar plates, so its appear as white to grey colonies (1-2) $\mathrm{mm}$ in diameter (15). While macroscopic features of Streptococcus pyogenes isolates reported G 
+ve cocci chains or pairs non-motile bacterium and non-spore forming cells (15).

\section{Biochemical tests}

All 27 Streptococcus pyogenes isolates were positive for oxidase, catalase, Simmon's citrate utilization, in dole negative and negative MR-VP tests. It did not ferment carbohydrates, but many isolates oxidize glucose. All these results had confirmed by Mini API 20 STREP system and VITEK 2 system Streptococcus pyogenes (16).

\section{Antibiotic susceptibility}

Antibiotic Susceptibility of Streptococcus Pyogenes isolates had showed different levels of sensitivity and resistance as follow:

\section{Benzyl penicillin}

Streptococcus pyogenes isolates had showed highly sensitivity 25(92.6\%) and 2 (7.4\%) resistant isolates, with highly significant differences $(\mathrm{P}<0.01)$. These findings agree with Chaurasia et al., (2014) (18) who mentioned that the sensitivity of Streptococcus pyogenes isolates to benzyl Penicillin was 80.2(78.3\%). While Muluye et al., (2014) (19) reported that Streptococcus pyogenes isolates were resistance to the benzyl Penicillin 628 (59.8\%), and these results disagree with current results (Table 1).

\section{Ampicillin}

In current, study Streptococcus pyogenes isolates were sensitive to Ampicillin antibiotic $24(88.88 \%)$, resist $3(11.12 \%)$ and observed highly significant differences $(\mathrm{P}<0.01)$. (Table 1) Prajapati et al., (2014) (20) reported that the Streptococcus pyogenes isolates were resistance to Ampicillin 51 (7.8\%), through that these results nearly with current study.

Sanjeeb et al., (2014) (21) stated that the Streptococcus pyogenes isolates were resistance to Ampicillin $123(38.1 \%)$ and these results disagree with current study.

\section{Penicillin}

Results of susceptibility was that Streptococcus pyogenes isolates were sensitive to Penicillin 16(59.26\%), resistance $11(40.74 \%)$ and there were non-significant differences $(\mathrm{P}>0.05)$.

Curtin-Wirt et al., (2003) (22) reported that isolates of Streptococcus pyogenes were sensitive to Penicillin 276(64\%) these results agree to current study. So results of current study were disagreed with Al-Saimary (2011) (11) who reported that isolates of Streptococcus pyogenes were resist to Penicillin 24(100\%).

Fig.1 Antibiotic susceptibility pattern of Streptococcus pyogenes isolates

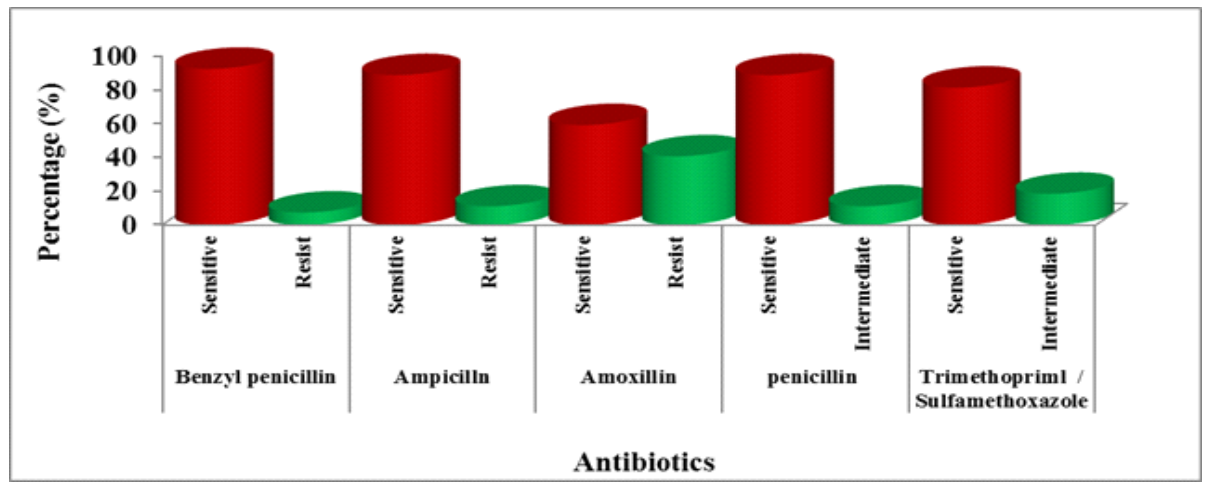


Fig.2 Antibiotic sensitivity pattern of Streptococcus pyogenes isolates

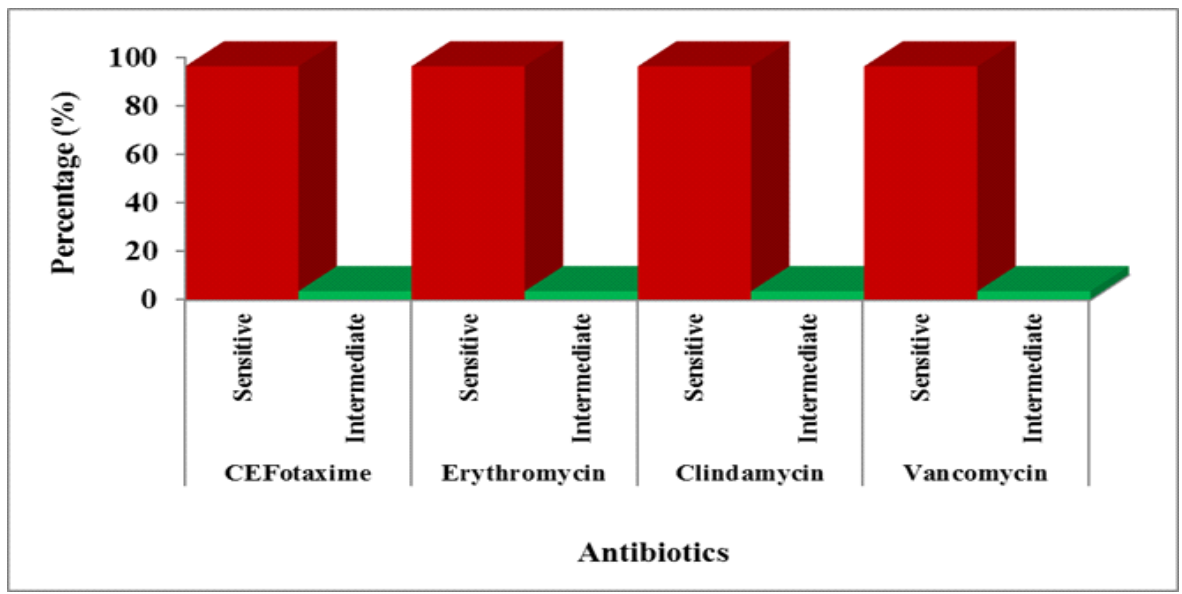

Table.1 Antibiotic Susceptibility Pattern for Streptococcus pyogenes

\begin{tabular}{|c|c|c|c|c|}
\hline Antibiotic & & No. & $\%$ & Z-test (P-value) \\
\hline \multirow{2}{*}{ Benzyl penicillin } & Sensitive & 25 & $92.6 \%$ & \multirow{2}{*}{$\begin{array}{l}P=0.00 \text { HS } \\
(P<0.01)\end{array}$} \\
\hline & Resist & 2 & $7.4 \%$ & \\
\hline \multirow{2}{*}{ Ampicillin } & Sensitive & 24 & $\mathbf{8 8 . 8 8 \%}$ & \multirow{2}{*}{$\begin{array}{l}P=0.00 \\
\text { HS }(P<0.01)\end{array}$} \\
\hline & Resist & 3 & $11.12 \%$ & \\
\hline \multirow{2}{*}{ Penicillin } & Sensitive & 16 & $59.26 \%$ & \multirow{2}{*}{$\begin{array}{l}P=0.442 \text { NS } \\
(P>0.05)\end{array}$} \\
\hline & Resist & 11 & $40.74 \%$ & \\
\hline \multirow{2}{*}{$\begin{array}{l}\text { Trimethoprim } \\
\text { /Sulfamethoxazole }\end{array}$} & Sensitive & 22 & $81.48 \%$ & \multirow{2}{*}{$\begin{array}{l}P=0.002 H S \\
(P<0.01)\end{array}$} \\
\hline & Intermediate & 5 & $18.52 \%$ & \\
\hline \multirow{2}{*}{ Cefotaxim } & Sensitive & 26 & $96.3 \%$ & \multirow{2}{*}{$\begin{array}{l}P=0.00 \text { HS } \\
(P<0.01)\end{array}$} \\
\hline & Intermediate & 1 & $3.7 \%$ & \\
\hline \multirow{2}{*}{ Erythromycin } & Sensitive & 26 & $96.3 \%$ & \multirow{2}{*}{$\begin{array}{l}P=0.00 \text { HS } \\
(P<0.01)\end{array}$} \\
\hline & Intermediate & 1 & $3.7 \%$ & \\
\hline \multirow{2}{*}{ Clindamycin } & Sensitive & 26 & $96.3 \%$ & \multirow{2}{*}{$\begin{array}{l}P=0.00 \text { HS } \\
(P<0.01)\end{array}$} \\
\hline & Intermediate & 1 & $3.7 \%$ & \\
\hline \multirow{2}{*}{ Vancomycin } & Sensitive & 26 & $96.3 \%$ & \multirow{2}{*}{$\begin{array}{l}\mathbf{P}=0.00 \mathrm{HS} \\
(\mathbf{P}<\mathbf{0 . 0 1})\end{array}$} \\
\hline & Intermediate & 1 & $3.7 \%$ & \\
\hline
\end{tabular}

Trimethoprim/sulfamethoxazole or cotrimoxazole

The results of study were reported that Strep pyogenes isolates showed sensitive $22(81.48 \%)$ and intermediate $5(18.52)$ with highly significant differences $(\mathrm{P}<0.01)$. Agrawal et al., (2014) (12) showed
Streptococcus pyogenes isolates resistant to co-trimoxazole $100 \quad(66.67 \%)$, and these findings differ from results of present study. While Bergmann, (2014) (13) explained that Streptococcus pyogenes isolates showed intermediate resistance to trimethoprim, which were $69(1.5 \%)$ and these results similar current study (Figure 1). 


\section{Cefotaxim}

The results of present study showed a highly significant differences $(\mathrm{P}<0.01)$. And the sensitivity to cefotaxim were $26(96.3 \%)$, intermediate $1(3.7 \%)$.These results disagree with Ramadan et al.,(2010) (23) who reported that the Streptococcus pyogenes isolates resistant to Cefotaxim42(38\%) (Figure 2).

\section{Erythromycin}

In this study, Streptococcus pyogenes isolates were sensitive to Erythromycin 26(96.3\%), intermediate $1(3.7 \%)$ with highly significant differences $(\mathrm{P}<0.01)$. These results agree with Prajapati et al., (2012) (20) who showed that the Streptococcus pyogenes isolates sensitive to $47(92.2 \%)$. In addition, these results agreed with results of Ray et al., (2004) (24) reported that Streptococcus pyogenes isolates sensitive to Erythromycin which was 103 $(89.6 \%)$.

\section{Clindamycin}

Clindamycin susceptibility results showed that there were 26 isolates of Streptococcus pyogenes appeared $96.3 \%$ sensitivity and 1 $(3.7 \%)$ intermediate with highly significant differences $(\mathrm{P}<0.01)$. These findings approach with Ray et al., (2004) (24) who showed that the Streptococcus pyogenes isolates were sensitive to Clindamycin with 115 (100\%). While Glauber et al., (2014) (25) reported that resistance of same isolates to Clindamycin were 91 (15.4\%). Catalina, et al., (2011) (26) reported that the Streptococcus pyogenes isolates sensitive to Clindamycin were $(85 \%)$ and these findings disagree with results of present study.

\section{Vancomycin}

Results of Streptococcus pyogenes isolates sensitivity was showed $26(96.3 \%)$ and intermediate was 1 (3.7) with non-significant differences $(\mathrm{P}<0.01)$. These obtained results agree with Agrawal et al., (2014) (12) who presented that $6(100 \%)$ of Streptococcus pyogenes isolates were sensitive to Vancomycin. While Capoor et al., (2006) (27) disagree with current study when reported that $10(29.4 \%)$ of Streptococcus pyogenes isolates sensitive to Vancomycin.

\section{References}

Jawetz Melnick, and Adelberg's. (2014). Medical microbiology $24^{\text {th }}$ edn. Pp. 978.

Nobbs AH, Lamont RJ, Jenkinson HF. (2009). Streptococcal adherence and colonization. Microbiology and Molecular Biology Reviews MMBR, 73: 407-450.

WHO. (2014). World Health Organization. First global report on antibiotic resistance reveals serious, worldwide threat to public health

Wong, S. S. and Yuen, K.Y. (2012). Streptococcus pyogenes and reemergence of scarlet fever as a public health problem. Emerging Microbes \& Infections. 1: 1038-1039.

You, Y.H., Song, Y.Y. and Yan, X. M. (2013). Molecular Epidemiological Characteristics of Streptococcus pyogenes strains involved in an outbreak of scarlet fever in China. Biomed Environ Sci. 26: 877-885.

Ibrahim, S. I., Rehab, H. E., Ahmed, A. E., Mohammad, W. E., Wael, M. A., Abdel, wahab, M. H., Inas, I. B. (2014). Emerging Resistance to Erythromycin and Penicillin among Streptococcus Pyogenes Isolates in Zagazig, Egypt. In J. Curr. Microbial App. Sci., 3(10):750756.

Sharma, Y., Vishwanath, S., Bairy, I. (2010). Biotype and antibiotic resistance pattern of group A Streptococci. Indian $J$ Pathol Microbial. 53: 187-188. 
Bourbeau, P.P. (2003). Rule of the microbiology laboratory in diagnosis and management of pharyngitis. J. Clin. Microbiol., 41: 3467-3472.

You, Y.H., Song, Y.Y. Yan, X. M. (2011). Molecular

Epidemiological

Characteristics of Streptococcus pyogenes strains involved in an outbreak of Scarlet Fever in China. Biomed Environ Sci., 26: 877-885.

Beres, S.B., Richter, E.W., Nagiec, M.J. (2006). Molecular genetic anatomy of inter-and intra-serotype variation in the human bacterial pathogen group A Streptococcus. Proc Nat Acad Sci., 103: 7059-7064.

Al-Saimary, I. E. (2011). Antibiogram and multidrug resistance patterns of Staph. aureus (MDRSA) associated with postoperative wound infections in Basra- Iraq Med. Practice and Review. 2 (6): 66-72.

Agrawal, A., Kumar, D., Goyal, A., Gupta, R., Suneel, B. (2014). India IOSR J. of Den. Med. Sci. (IOSR-JDMS). 13(3):5155.

Bergmann, R., VanDer, Linden. M., Chhatwal, G.S., Nitsche-Schmitz, D.P. (2014). Factors that cause trimethoprim resistance in Streptococcus pyogenes. Antimicrobial Agents and Chemotherapy. 58(4): 2281-2288.

Mims C, Goering RV, Dockrell HM, Wakelin D, Zuckerman M, Chiodini PL, Roitt IM. Mims Medical Microbiology $4^{\text {th }}$ ed., ElsevierMosby, USA, 2008.

Salma AM, Hossain MA, Musa AK, Shamsuzzaman AK. et al., (2010). Aerobic and anaerobic bacterial causes of puerperal sepsis at Mymensingh medical college hospital. Mymensingh Med J., 19(1):10-15.

McCall, R.B. (1980). Fundamental Statistics for Psychology Harcourt brace. Jovanvich, Inc., (3):102-114.

CLSI, (Clinical and Laboratory Standards
Institute). (2011). Performance standard for antimicrobial susceptibility testing; Twenty-First informational supplement. Pp. 31.

Chaurasia, A. K., Shridha, C., Shubha, C., Sushmita, C. (2014). Efficacy of antibiotics against sclerotium rolfsii causing foot-rot of brinjal. International J., 3(1): 1-4.

Muluye' D., Wondimeneh, Y., Ferede, G., Nega, T., Adane, K., Biadgo, B., Tesfa, H., Feleke, Moges. (2014). Bacterial isolates and their antibiotic susceptibility patterns among patients with pus and/or wound discharge at Gondar Univ. hospital. BMC Res Notes. 7: 619.

Prajapati, A., Rai, S. K., Mukhiya, R.K., Karki, A. B. (2014). Study on carrier rate of Streptococcus pyogenes among the Sch children and antimicrobial susceptibility pattern of isolates. Nepal Med Coll J. 14 (3): 169-171.

Sanjeeb, Sharma; Sh, Praveen; Kh, Sulochana. Devi., Biswajeet; Sahoo. Waikhom, Shashi. Singh; Thokchom, Devaraj. Singh. (2014). Prevalance of Streptococcus pyogenes infection in children aged between 5 to 15 years with acute tonsillopharyngitis and its antibiogram. IOSR J. of Dental and Med. Sci., 13(11): 50-55.

Curtin, D. Correne., Janet, R. Casey., Patrick, C. Murray., Carolyn, T. Cleary., William, J. Hoeger., Steven, M. Marsocci., Marie, Lynd. Murphy; Anne, B. (2003). Efficacy of Penicillin vs. Amoxicillin in Children with Group A Beta Hemolytic Streptococcal Tonsillopharyngitis. Clin Pediater. 42(6):519-26.

Ramadan, Hassan; Rasha, Barwa; Hanan, Shehata. R., (2010). Antimicrobial Resistance Genes and Some Virulence Factors in Escherichia coli and Streptococcus pyogenes Isolated from 
Mansoura Univ. Hospitals. Egyptian J. of Med. Microbiology, January.19(1):127.

Ray, C., George, R. Kenneth, J., Kenneth, R. (2004). Sherri's Med. Microbiology: An Introduction to Infec. Diseases, $4^{\text {th }}$ edn. McGraw Hill. Pp. 237.

Glauber, P. A., Rôde, B.B. S., Felipe, P.G. N., Rosana, R. B. (2014). Antimicrobial susceptibility patterns, emm type distribution and genetic diversity of Strep pyogenes recovered in Brazil. Mem Inst Oswaldo Cruz, Rio de
Janeiro. 109(7): 935-939.

Catalina, Gavriliu. Liana-Popescu. G. A., Popescu, Cristina. Streinu-Cercel. A. (2011). Antimicrobial treatment for infections due to beta hemolytic group a Streptococcus. Therapeutics, Pharmacology and Clinical Toxicology, 15(3): 221-224.

Capoor, M. R.., Nair, D., Deb, M., Batra, K., Aggarwal, P. (2006). Resistance to Erythromycin and Rising Penicillin MIC in Streptococcus pyogenes. J. Infect Dis. 59: 334-336.

\section{How to cite this article:}

Abbas Zeki Mahdi, Jawad Hamid Hassan and Khalid Sh. Jebur. 2017. Antibiotic Susceptibility of Streptococcus pyogenes Isolated from Otitis Media and Tonsillitis among Children Patients. Int.J.Curr.Microbiol.App.Sci. 6(8): 998-1004. doi: https://doi.org/10.20546/ijcmas.2017.608.123 